\title{
ПРОМЫШЛЕННАЯ ПОЛИТИКА В ЕС
}

Аннотация. На нынешнем этапе развития мировой экономики понятия «промышленная политика» и «политика повышения национальной конкурентоспособности» становятся синонимами. Статья посвящена анализу промышленной политики в Европейском союзе. Даётся оценка состоянию и перспективам её дальнейтего развития и тесного взаимодействия с инновационной составляющей экономического курса ЕС. Подчёркиваются проблемь и неравномерность финансирования НИОКР в государствах - членах Евросоюза. Отмечается взаимосвязь конкурентоспособности европейской промышленности и качества профессиональной подготовки рабочей сильл.

Ключевые слова: Европейский союз, Европейская комиссия, промышленная политика, инновачии, конкурентоспособность.

Европейский союз (ЕС) сохраняет сегодня мировое лидерство в таких сферах промышленности как фармацевтика, машиностроение, химическое производство и термоядерная энергетика, динамично совершенствует оптические, информационные и биотехнологии. При этом имеются и слабые места индустриального развития. Это, прежде всего, неадекватные современным условиям хозяйствования расходы на НИОКР ${ }^{1}$ и низкий уровень знаний в области информационных систем и технологий почти у половины населения. В то время как «90\% всех рабочих мест в скором времени потребуют определённого уровня цифровых навыков; но сегодня у $40 \%$ европейцев его нет» ${ }^{2}$.

В соответствии с Договором о функционировании Европейского союза к одной из сфер компетенции ЕС относится поддержка, координация и дополнение деятельности стран-членов в сфере промышленности. Союз и государства-члены заботятся об обеспечении необходимых условий для конкурентоспособности промышленности. Их совместная деятельность направлена на ускорение адаптации промышленности к структурным изменениям, содействие формированию благоприятной среды для развития компаний (особенно в сфере малого и среднего бизнеса) и сотрудничества между предприятиями, содействие инновационной политике и $\mathrm{HИР}^{3}$. Евросоюз ставит цель укрепить научно-технологические основы промышленности с помощью создания европейского пространства научных исследований со свободным передвижением учёных, знаний и технологий, транспарентных условий конкурентоспособности.

В отраслевой структуре экономики Европейского союза индустриальный сектор зани-

(C) Говорова Наталья Викторовна - кандидат экономических наук, ведущий научный сотрудник Отдела экономических исследований ИЕ РАН. Адрес: 125009, Россия, Москва, ул. Моховая, д. 11, стр. 3. E-mail: n_govorova@mail.ru.

DOI: http://dx.doi.org/10.15211/vestnikieran12019108113

${ }^{1}$ НИОКР - исследования и экспериментальные разработки включают в себя творческую работу, проводимую на систематической основе с целью увеличения объёма знаний, в том числе знаний о человеке, культуре и обществе, и использования этого запаса знаний для новых разработок.

2 European Commission. Press release. Ten actions to help equip people in Europe with better skills. URL: http://europa.eu/rapid/press-release_IP-16-2039_en.htm.

${ }^{3}$ Сидорова Е.А. Промышленная политика и её финансирование в ЕС. Научно-аналитический вестник ИЕ РАН, 2018, №6. DOI: http://dx.doi.org/10.15211/vestnikieran620186. 
мает менее $20 \%$, а вместе со строительством, горно-шахтным и коммунальным хозяйством составляет около $30 \%{ }^{1}$. Он включает широкий спектр видов деятельности и методов производства: от небольших предприятий, использующих традиционные методы производства, до крупных компаний, производящих сложные продукты, к примеру, летательные аппараты. Примерно каждое десятое предприятие в нефинансовом хозяйственном секторе ЕС-28 относится к производственному; в общей сложности - это 2,1 млн единиц, в которых задействовано 29,9 млн человек (21,8\% всех занятых), ежегодно вносящих вклад в ВВП порядка 2000 млрд евро (крупнейшие подсектора с точки зрения добавленной стоимости и занятости - производство машин и оборудования, автотранспортных средств, прицепов и полуприцепов, и пищевых продуктов). Производительность труда и средние расходы на персонал превышают средние показатели экономики за пределами финансового сектора.

Стратегия «Европа 2020» ${ }^{2}$, десятилетняя программа Европейского союза по стимулированию разумного, сбалансированного и справедливого роста и повышению конкурентоспособности определила науку, содействие развитию образования и инноваций как ключевые движущие силы прогресса. Целям Стратегии служат приоритеты промышленной политики EC, сформулированные в 2010 г. в документе «Промышленная политика для эпохи глобализации» ${ }^{3}$. Его отличительной чертой является интегрированный и сбалансированный подход к конкурентоспособности с учётом требований глобализации мировой экономики. Такой подход даёт возможность оптимального взаимодействия горизонтальных и отраслевых направлений деятельности, включающий формирование целостной цепи поставок от доступа к сырью и переработки материалов до постпродажного обслуживания. Предложенный Европейской комиссией (ЕК) новый курс ставит конечной целью улучшение предпринимательской среды, в том числе для малого и среднего бизнеса (МСБ), формирующего $2 / 3$ занятости в промышленности ЕС и основную долю роста этого сектора экономики. Такой курс позволяет ЕК на регулярной основе анализировать политику и достижения Евросоюза и государств-членов в области конкурентоспособности.

Впервые комплексный подход к промышленной политике был изложен в июле 2005 г. в сообщении Комиссии «Реализация Лиссабонской программы Сообщества: политические рамки для укрепления производства в ЕС - к более интегрированному подходу к промышленной политике» ${ }^{4}$. В дальнейшем действия Комиссии были направлены на обеспечение комплексного пакета мер по стимулированию более устойчивого потребления и производства при одновре́менном повышении конкурентоспособности европейской экономики. С этой целью в июле 2008 г. был разработан «План действий по устойчивому потреблению и производству и ус-тойчивой промышленной политике» ${ }^{5}$. В 2014 г. была обнародована инициатива ЕК «Для возрождения европейской промышленности» ${ }^{6}$, в которой обозначены цели и действия в этой сфере после финансово-экономического кризиса 2008-2099 гг., необходимость повышения

\footnotetext{
${ }^{1}$ Eurostat. Statistics Explained. Manufacturing statistics - NACE Rev. 2. URL: https://ec.europa.eu/eurostat/statisticsexplained/index.php?title=Manufacturing_statistics_-_NACE_Rev._2\#Size_class_analysis.

${ }^{2}$ Communication from the Commission Europe 2020 . A strategy for smart, sustainable and inclusive growth. Brussels, 3.3.2010 COM (2010) 2020 final.

${ }^{3}$ Communication from the commission An Integrated Industrial Policy for the Globalisation Era Putting Competitiveness and Sustainability at Centre Stage. SEC (2010) 1272. SEC (2010) 1276. Brussels, 28.10.2010. COM (2010) 614 final.

${ }^{4}$ European Commission. «Implementing the community Lisbon programme: A policy framework to strengthen EU manufacturing - towards a more integrated approach for industrial policy». COM (2005) 474.

5 Communication from the Commission on the Sustainable Consumption and Production and Sustainable Industrial Policy Action Plan. \{SEC (2008) 2110\}. \{SEC (2008) 2111\}. Brussels, 16.7.2008. COM(2008) 397 final.

6 Communication from the Commission. For a European Industrial Renaissance \{SWD (2014) 14 final $\}$. Brussels, 22.1.2014 COM (2014) 14 final.
}

Научно-аналитический вестник ИЕ РАН, 2019, №1 
инвестиций в инновации и ресурсоэффективность, оптимизации законодательства, совершенствование Акта для малого бизнеса (Small Business Act) и Плана действий развития предпринимательства (Enterpreneurship Action Plan).

В сентябре 2017 г. в ЕК представила новую Стратегию промышленной политики ЕС ${ }^{1}$. Её основными элементами стали:

- комплексный пакет для усиления кибербезопасности отрасли. Он включает в себя создание Европейского центра исследований и компетенции в области кибербезопасности для поддержки развития технологий и промышленного потенциала в этой области, а также обще-европейской схемы сертификации продуктов и услуг, признанной во всех государствах-чле-нах;

- предложение по Положению о свободном потоке неличных данных, которое позволит свободно распространять их в целях модернизации отрасли, создавая действительно единое европейское пространство данных;

- новая серия мероприятий по циркулярной экономике, включая стратегию по пластмассам и меры по улучшению производства возобновляемых биологических ресурсов и их превращения в биопродукты и биоэнергетику;

- ряд инициатив по модернизации структуры интеллектуальной собственности, в том числе отчёт о функционировании Директивы по защите прав интеллектуальной собственности и сообщение о сбалансированной, чёткой и предсказуемой европейской системе лицензирования патентов;

- инициатива по улучшению функционирования государственных закупок в ЕС, включая руководства для органов власти, планирующих крупные инфраструктурные проекты;

- распространение Повестки дня навыков (New Skills Agenda for Europe) на новые ключевые отрасли промышленности: строительство, производство стали и бумаги, экологически чистые технологии и возобновляемые источники энергии, морские перевозки;

- стратегия устойчивого финансирования для лучшей ориентации потоков частного капитала в соответствующие инвестиции;

- инициативы по сбалансированной торговой политике и европейские рамки для проверки прямых иностранных инвестиций, которые могут представлять угрозу безопасности или общественному порядку;

- пересмотренный список критически важного сырья, для обеспечения надёжных поставок для обрабатывающей промышленности;

- новые предложения по ужесточению стандартов выбросов $\mathrm{CO}_{2}$ для легковых автомобилей и микроавтобусов, план действий по созданию инфраструктуры альтернативных видов топлива.

Промышленная и инновационная политики тесно связаны. В современной научной литературе уже присутствует понятие «промышленная инновационная политика». Развитие инновационных нано- и биотехнологий позволяет обеспечивать производство востребованных не только в настоящем, но и в будущем товаров и услуг, а значит ведёт к повышению международной конкурентоспособности промышленности ЕС. Однако результаты зависят от соответствующего финансирования, которое существенно отстаёт от затрат Южной Кореи, США и Японии ${ }^{2}$. Среди целей Стратегии «Европа 2020»- увеличение финансирования НИОКР до 3\% ВВП в целом по ЕС (бо́льшая часть государств-членов приняли собственные целевые уста-

\footnotetext{
${ }^{1}$ Communication from the Commission. Investing in a smart, innovative and sustainable Industry. A renewed EU Industrial Policy Strategy. Brussels, 13.9.2017. COM (2017) 479 final.

2 The EU in the world 2018 edition. Luxembourg: Publications Office of the European Union, 2018. P. 112. doi:10.2785/990579.
}

Научно-аналитический вестник ИЕ РАН, 2019, №1 
новки). Однако подавляющее большинство стран группировки далеки от её выполнения (табл.), что ставит под угрозу честолюбивые планы Европы на мировое научно-технологическое лидерство.

Таблица

Валовые внутренние расходы на НИОКР, \% от ВВП, 2017 г.

\begin{tabular}{|l|c|l|c|l|c|}
\hline $\mathbf{E C - 2 8}$ & $\mathbf{2 , 0 7}(\mathbf{3 , 0})^{*}$ & Испания & $1,2(2,0)$ & Нидерланды & $1,99(2,5)$ \\
\hline ЕС-19 & $2,17(:)$ & Франция & $2,25 * *(3,0)$ & Австрия & $3,16(3,76)$ \\
\hline Бельгия & $2,58(3,0)$ & Хорватия & $0,86(1,4)$ & Польша & $1,03(1,7)$ \\
\hline Болгария & $0,75(1,5)$ & Италия & $1,35(1,53)$ & Португалия & $1,32(2,7)$ \\
\hline Чехия & $1,79(1,0)$ & Кипр & $0,56(0,5)$ & Румыния & $0,5(2,0)$ \\
\hline Дания & $3,06(3,0)$ & Латвия & $0,51(1,5)$ & Словения & $1,86(3,0)$ \\
\hline Германия & $3,02(3,0)$ & Литва & $0,88(1,9)$ & Словакия & $0,88(1,2)$ \\
\hline Эстония & $1,29(3,0)$ & Люксембург & $1,26(2,3)$ & Финляндия & $2,76(4,0)$ \\
\hline Ирландия & $1,05(2,0)$ & Венгрия & $1,35(1,8)$ & Швеция & $3,33(4,0)$ \\
\hline Греция & $1,13(1,21)$ & Мальта & $0,55(2,0)$ & Великобритания & $1,67(:)$ \\
\hline
\end{tabular}

* В скобках приведены национальные цели стран ЕС в сфере финансирования НИОКР.

** 2016 г.

Источник: Eurostat.

В соответствии с доступными статистическими данными, расходы на НИОКР превысили целевой общеевропейский показатель только в Швеции, Австрии, Германии и Дании, в аутсайдерах - Румынии, Болгарии, Мальте, Латвии и Кипре. Последний при этом уже достиг свою национальную цель, так же, как и Чехия. В связи с вышеизложенным Еврокомиссия 7 июня 2018 г. предложила увеличить до 97,6 млрд евро бюджет перспективной программы научных исследований «Горизонт Европа» (2021-2027 гг.) по сравнению с 80 млрд евро текущей программы «Горизонт 2020», а также поддержку научных исследований (с акцентом на проблемах здравоохранения и медицинском оборудовании) и подготовку кадров в сферах ядерной энергетики, ядерной безопасности и радиационной защиты Европейского сообщества по атомной энергии $(2,4 \text { млрд евро })^{1}$. Среди важнейших задач «Горизонт Европа» - приумножение научно-технологического потенциала ЕС за счёт увеличения инвестиций в квалификацию персонала и в авангардные научные исследования; повышение конкурентоспособности промышленности за счёт поддержки инноваций, формирующих перспективные рынки; лидерство ЕС в сфере борьбы с изменениями климата и иными вызовами, негативно влияющими на качество жизни населения ${ }^{2}$. В основу реализации программы «Горизонт Европа» положен принцип открытости науки, а также предусмотрен новый тип партнёрства между промышленными предприятиями, европейскими программами и фондами, гражданским обществом и финансовыми учреждениями.

Европейский союз стремится к завоеванию передовых позиций в глобальной конкуренции, достижению лидерства на рынках интеллектуальных услуг и высокотехнологичных товаров на базе всеобщей доступности качественных образования и здравоохранения, сбалансированности регионального развития, инноваций и оптимизации использования человеческого потенциала. Европейская промышленная политика носит интегральный характер, будучи взаимосвязанной с другими направлениями экономической политики, прежде всего, инновационной и экологической. Нынешние реалии в экономической сфере показывают, что конкурентоспособность промышленности во всё большей мере зависит от таких факторов, как качество трудовых ресурсов, прочность связей между бизнесом, высшими учебными зав-

\footnotetext{
${ }_{1}^{1}$ European Commission - Press release. EU budget: Commission proposes most ambitious Research and Innovation Programme. URL: http://europa.eu/rapid/press-release_IP-18-4041_en.htm.

${ }^{2}$ European Commission. EU Budget for the Future. Horizon Europe. UR: https://ec.europa.eu/commission/sites/betapolitical/files/budget-may2018-research-innovation_en.pdf.
}

Научно-аналитический вестник ИЕ РАН, 2019, №1 
едениями и научно-исследовательскими институтами, скорость распространения в промышленности технологических и управленческих инноваций. Значительное воздействие на эффективность промышленной политики оказывает обеспечение соответствующей профессиональной подготовки и переподготовки рабочей силы в течение всей жизни. Общей тенденцией в европейской практике является формирование индустриальной политики, которая позволяет сочетать заинтересованность различных хозяйственных субъектов, принимая во внимание интересы как нынешнего, так и будущих поколений.

\section{Список литературы}

Сидорова Е.А. Промышленная политика и её финансирование в ЕС. Научно-аналитический вестник ИЕ РАН, 2018, №6. DOI: http://dx.doi.org/10.15211/vestnikieran620186.

\section{References}

European Commission. Press release. Ten actions to help equip people in Europe with better skills. URL: http://europa.eu/rapid/press-release_IP-16-2039_en.htm.

Consolidated Version of the Treaty on the Functioning of the European Union, Art. 6, 173, 179, 189. Official Journal of the European Union. C 83. 30.03.2010.

The EU in the world 2018 edition. Luxembourg: Publications Office of the European Union, 2018. DOI:10.2785/990579.

Eurostat. Statistics Explained. Manufacturing statistics - NACE Rev. 2 URL: https://ec.europa. eu/eurostat/statistics-explained/index.php?title=Manufacturing_statistics_-_NACE_Rev._2\#Size class_analysis.

Communication from the Commission. Europe 2020. A strategy for smart, sustainable and inclusive growth. Brussels, 3.3.2010 COM (2010) 2020 final.

Communication from the Commission. An Integrated Industrial Policy for the Globalisation Era Putting Competitiveness and Sustainability at Centre Stage. SEC (2010) 1272. SEC (2010) 1276. Brussels, 28.10.2010. COM (2010) 614 final.

European Commission. «Implementing the community Lisbon programme: A policy framework to strengthen EU manufacturing - towards a more integrated approach for industrial policy». COM (2005) 474.

Communication from the Commission. Investing in a smart, innovative and sustainable Industry. A renewed EU Industrial Policy Strategy. Brussels, 13.9.2017. COM (2017) 479 final.

Communication from the Commission on the Sustainable Consumption and Production and Sustainable Industrial Policy Action Plan. \{SEC (2008) 2110\}. \{SEC (2008) 2111\}. Brussels, 16.7.2008. COM (2008) 397 final.

Communication from the Commission. For a European Industrial Renaissance \{SWD (2014) 14 final \}. Brussels, 22.1.2014 COM (2014) 14 final.

European Commission - Press release. EU budget: Commission proposes most ambitious Research and Innovation Programme. URL: http://europa.eu/rapid/press-release_IP-18-4041_en.htm.

European Commission. EU Budget for the Future. Horizon Europe. URL: https://ec.europa.eu/ commission/sites/beta-political/files/budget-may2018-research-innovation_en.pdf.

Sidorova E.A. Promyshlennaya politika i eyo finansirovanie v ES. Nauchno-analiticheskij vestnik IE RAN, 2018, №6. DOI: http://dx.doi.org/10.15211/vestnikieran620186. 


\section{Industrial policy in the EU}

Author. Natalia Govorova, Candidate of Sciences (Economics), Leading Researcher, Institute of Europe, Russian Academy of Sciences. Address: 11-3, Mokhovaya str., Moscow, Russia, 125009. E-mail: n_govorova@mail.ru.

Abstract. In developed EU countries, the concepts of «industrial policy» and «national competitiveness enhancement policy» are becoming synonymous. The paper is devoted to the analysis of industrial policy of the European Union. The estimation of its state and prospects as well as close interaction with the innovation component of the EU economic policy are given. The problems and uneven financing of R\&D in Member States are underlined. The interdependence of the competitiveness of European industry and the labor force 'skills is noted.

Key words: European Union, European Commission, industrial policy, innovation, competitiveness.

DOI: http://dx.doi.org/10.15211/vestnikieran12019108113 